\title{
"young dentists meeting" am 23./24.Oktober 2015: Praxisnahe Workshops und Tipps zur Praxisführung
}

\section{Implantatchirurgie Step-by-Step mit praktischen Übungen am Kunststoffkiefer}

In einem praxisnahen Hands-on-Workshop vermittelt PD Dr. Dr. Marcus O. Klein aus Düsseldorf in Zusammenarbeit mit der Fa. Straumann die theoretischen Grundlagen der Implantologie und gibt einen Überblick über den Status quo sowie neue Materialien und Oberflächen. In begleitenden Übungen haben die TeilnehmerInnen die Möglichkeit, ein Implantat im Kunststoffkiefer zu inserieren.

\section{Häuptlinge und Indianer - Praxisführung konkret}

In dem Seminar von Dipl.-Päd. Herbert Prange erfahren Sie, wie Sie als Führungsperson Ihrer komplexen Aufgabe und vielschichtigen Verantwortung gerecht werden, wie Sie Ihre Patienten richtig einschätzen, im Team mehr Spaß haben und welche Erkenntnisse Ihnen dabei die moderne Gehirnforschung liefert.

Anmeldung unter www.young-dentists.de

\section{Kongress des ZoRA KompetenzNetzwerks vom 25. bis 27. September}

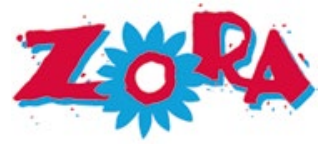

\section{Weimarer Forum mit Speed-Dating zur Praxisübernahme}

Das Weimarer Forum geht in eine neue Runde: Vom 25. bis 27. September beschäftigt sich der Kongress des ZoRA KompetenzNetzwerks unter dem Thema „Kompetenz schafft Perspektiven“ mit vielfältigen Themen, die neue Blickwinkel für das tägliche Berufsleben schaffen. Dem Thema Praxisabgabe/Praxisübernahme kommt in diesem Jahr besondere Bedeutung zu: Wer sich mit dem Gedanken beschäftigt, sich in eigener Praxis niederzulassen oder auf der Suche nach einem Nachfolger für seine Zahnarztpraxis ist, findet beim Weimarer Forum interessante Vorträge, Ansprechpartner und Gleichgesinnte. Diana Brendel von FIBU-doc Praxismanagement erläutert betriebswirtschaftliche und rechtliche Hintergründe und stellt anhand von Fallbeispielen die zentralen Abläufe dar. Für die ganz Eiligen findet am Freitagnachmittag ein Speed-Dating statt - die Gelegenheit für die Interessenten, um erste Kontakte zu knüpfen. „Mit diesem ersten Gespräch wollen wir beide Interessengruppen unkompliziert zueinanderführen“, erläutert die Vorsitzende des Freien Verbands Deutscher Zahnärzte e. V. (FVDZ) und ZoRA-Gründerin, Kerstin Blaschke, die Idee. Das ZoRA KompetenzNetzwerk steht für „Zahnärztinnen organisieren Recht und Arbeit“ und will praktikable und realitätsbezogene Lösungsansätze für die frauenspezifischen Anforderungen an den zahnärztlichen Beruf aufzeigen.

Erstmals bietet der FVDZ in diesem Jahr in Kooperation mit der Deutschen Bahn ein Veranstaltungsticket ab 99 Euro aus dem gesamten Bundesgebiet für die Hin- und Rückreise an. Fragen rund um den Kongress beantwortet Frauke Garstka in der Bonner FVDZBundesgeschäftsstelle unter der Telefonnummer 0228855732.
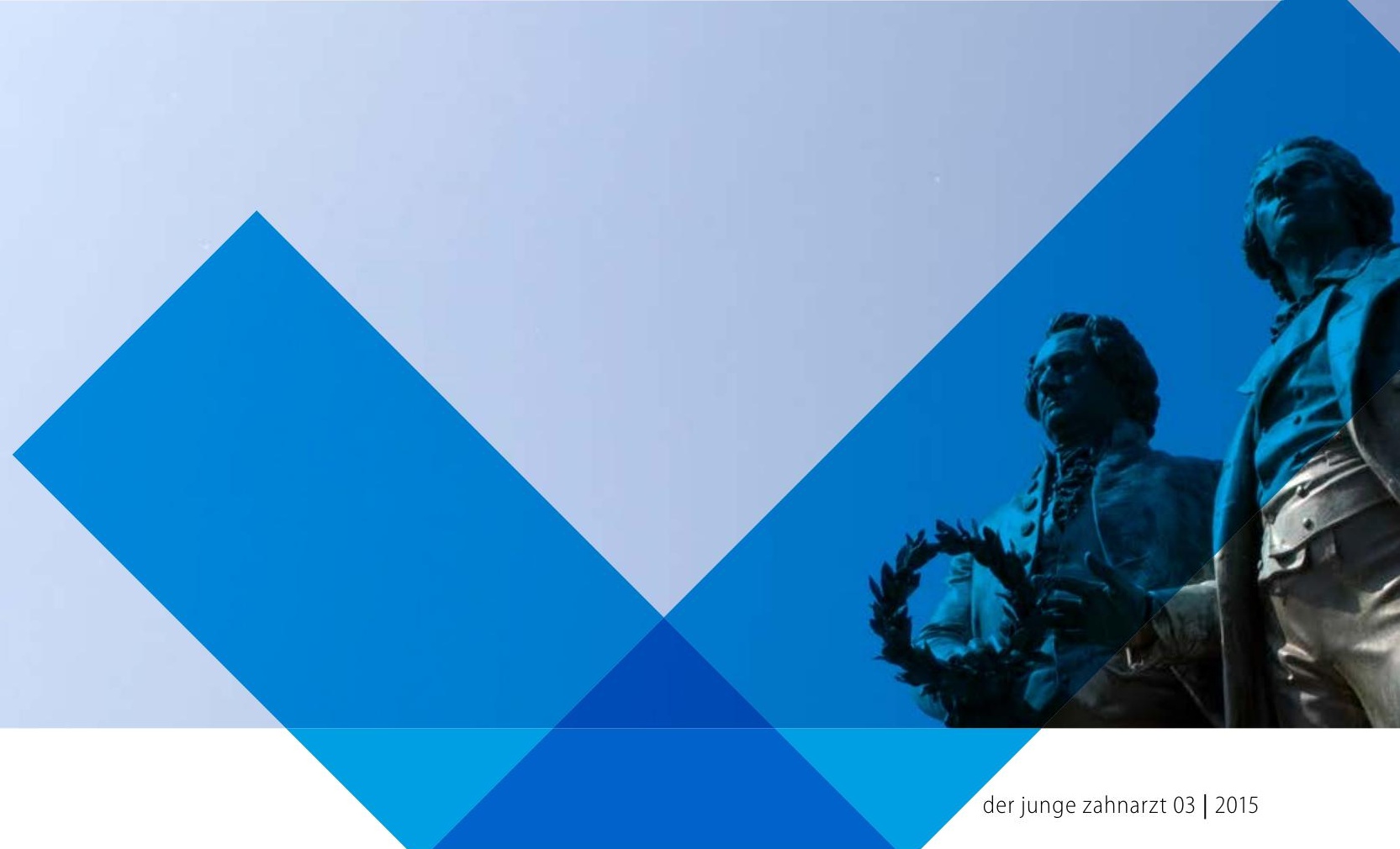